\title{
Evaluation of Gamification in E-Learning Systems for Elementary School Students
}

\author{
Mohammad T. Alshammari \\ College of Computer Science and Engineering, University of Ha'il, Ha'il, Saudi Arabia
}

\begin{abstract}
Gamification is often proposed as a promising solution to traditional e-learning systems by the incorporation of game elements and mechanisms to enhance the motivation, engagement and students' learning. However, most current studies lack careful and thorough experimental evaluation on the effect of gamification and are normally applied to science learning for adults which makes it difficult to generalize the findings to other learning domains. This paper addresses this issue by offering a controlled experiment with 58 elementary school students studying a course on Arabic language to investigate the learning effect of gamification. The results indicate that gamification positively enhances the learning outcome and students' learning motivation.
\end{abstract}

Keywords - Gamification, e-learning, evaluation, motivation, learning outcome

\section{Introduction}

Learning in traditional settings through classrooms may not always be applicable and appealing to students because there are some time and place constraints, and that each student needs to be motivated effectively which is a challenging task [1]. Also, the different characteristics of students cannot be taken into account in traditional classrooms to support each student [2].

DOI: 10.18421/TEM92-51

https://doi.org/10.18421/TEM92-51

Corresponding author: Mohammad T. Alshammari, College of Computer Science and Engineering, University of Ha'il, Ha'il, Saudi Arabia.

Email: md.alshammari@uoh.edu.sa

Received: 17 January 2020.

Revised: 22 April 2020.

Accepted: 29 April 2020.

Published: 27 May 2020.

(cc)BY-NC-ND(C) 2020 Mohammad T. Alshammari; published by UIKTEN. This work is licensed under the Creative Commons Attribution-NonCommercial-NoDerivs 4.0 License.

The article is published with Open Access at www.temjournal.com
This issue may discourage students from focussing on the learning process to understand, grasp and apply knowledge. Students in traditional settings may not always pay full attention and feel frustrated which can undesirably affect their satisfaction, engagement and learning outcomes. E-learning systems can be used alternatively or blended with classrooms to offer different levels of interactivity, deliver learning material in different multimedia types and enable learning opportunities anytime and anywhere [3]. However, traditional e-learning systems cannot always be useful since they provide the same learning material in the same order for all students irrespective of their different characteristics [4]. There is a need to incorporate different mechanisms to support the motivation of students as an essential factor so that the students can progress through their learning effectively [5].

Gamification is proposed often as a promising solution to be incorporated into e-learning systems in order to enhance the motivation and learning outcomes of students [6]. Gamification can be defined as the use of game mechanisms and strategies in different contexts other than entertainment (i.e., in a non-game context) [7]. Virtual rewards, points, levels and feedback are examples of game mechanisms [8]. These mechanisms can be incorporated in gamified elearning systems to be offered to students to support their learning [9]. The concept of gamification or gamified e-learning systems should be differentiated from the concepts of online educational games and game-based learning. Online educational games and game-based learning aim at offering implicitly embedded learning resources in an entraining approach implemented as a game so that students can play the game in order to learn [10].

Various efforts have been put in the field of gamification in online education [11], [12]. There are some encouraging results in terms of learning outcome [13], motivation [14], satisfaction [15] and engagement [16]. However, there is a lack of empirical evidence based on controlled and thorough experiments evaluating the effect of gamification on the learning process [11]. Most current studies are also limited to short-term evaluations with small sample sizes [5], [12]. Furthermore, the effect of 
gamification on young students, mainly on elementary school students are very few [17], [18]. In addition, the application domain of gamified elearning systems is related mostly to computer science education which raises the issue of generalization to other learning domains such as languages and mathematics [19].

More specifically, there is a research gap in evaluating the effect of gamification in terms of learning outcome and learning motivation on elementary school students focusing on the application domain of Arabic language learning. This paper addresses this issue by conducting a carefully controlled experimental evaluation with a longerterm study in a learning context. The experiment was conducted with sixth-grade elementary school students to study a course on Arabic language using a developed gamified e-learning system. The key research question addressed in this paper is "Does gamification in e-learning systems enhance the learning outcomes and learning motivation of sixthgrade students in learning a course on Arabic language?".

The paper is structured as follows. The next section provides related work. Section 3 details the evaluation method. Section 4 presents the results. Section 5 discusses the findings and concludes the paper.

\section{Related Work}

The concept of gamification was first introduced in 2010 and is defined as "the use of game design elements in non-game contexts" [7]. Gamification is still an active and trending research area [11]. This concept was largely adopted by different researchers in different disciplines such as health, business and education [5], [20]. Education is deemed as one of the essential application domains of gamification in order to enhance the learning outcome, engagement and motivation of students [21]. Gamification can be blended in classrooms, used independently via a gamified e-learning system or even to non-classroom courses [22]. Game elements such as points, levels, leader-boards, rewards and feedback can be incorporated in an e-learning system to provide the gamified learning experience to students [23].

One of the first empirical researches conducted to investigate the effect of gamification on learning achievement and learning satisfaction was conducted by [13]. A gamification tool was designed and integrated into an e-learning system focusing mainly on rewards and competition mechanisms, yielding promising results on learning achievements, particularly for specific practical learning activities. Also, a gamification framework was proposed and then deployed in an e-learning system primarily for elementary school students by [9]. Although they provided some results related to the usability of the system, no empirical evidence was generated regarding the applicability and the effect of the gamification framework particularly on learning outcomes and learning motivation. Similar work was also conducted in an elementary school learning context by [17]; they implemented a gamified mobile learning environment and conducted an experiment to evaluate the learning performance and motivation generating positive findings. Encouraging findings results were also obtained by an experimental evaluation of gamification on elementary school students studying a course on Geometry [16]. An evaluated approach to gamify programming learning was also proposed by [24] with the focus of leaderboard and badges as two central game elements. Their results indicated that there was a positive effect on learning engagement and a moderate effect on learning performance.

A more focused study on the effect of rewards as the main game element was presented in [25]. However, there were negative results in terms of learning engagement, motivation and learning achievements suggesting that more studies are needed. A study that focuses on the element of points only as a gamification feature presented in [26]; they conducted an experimental evaluation with adults and young students and showed no effect of the points to enhance the learning performance and motivation of both types of students. Conversely, a generic gamified blended learning approach that integrates several game elements, including points, badges and levels, was offered in [18]. Their results indicated a positive impact in terms of learning achievement and students' attitudes toward the learning lessons. This case is also similar to the research conducted by [27]; they used a freely available gamification platform called Kahoot for interclass competitions and claimed that they enhance the achievements and engagement of students. Recently, a developed gamified e-learning system called GAMESIT that integrates levels, avatars and badges to teach information technology was proposed and evaluated by [19]; promising results were also acquired from their experiments regarding learning achievement and engagement.

As evidenced by the pre-mentioned studies and recent reviews of gamification in education [6], [11], [12], [28], several issues can be identified. First, gamification still requires more careful experimental evaluations to investigate its effect on learning since most studies focus on short-term learning with limited sample sizes. Second, there is a need to apply gamification in different disciplines other than science learning to generalize the findings. Third, there were also very few studies that evaluate the 
effect of gamification on young students. Fourth, mixed findings were generated for different cultures, learning environments and the use of single or combined game elements. According to these issues, there is a research gap in conducting a more focused research study on the effect of gamification on young students applied in a different culture and application domain [28]. To the best of our knowledge, the study presented in this paper is one of the first careful studies that examine the impact of gamification on elementary school students applied to Arabic language learning.

\section{Method}

\subsection{Experimental Design}

A controlled experimental evaluation in a learning environment was designed to answer the research question. A between-subjects experimental design was employed where each participant experiences or is involved in one condition only. This particular design was administrated because it can help in avoiding the carryover and learning effect from one condition to another. Also, factors involved in this design, including age, gender, prior knowledge, study duration and experimental site, are controlled as possible to reduce the effect of the variability between participants on the results.

In this experiment, there were two experimental conditions/groups: the treatment group and the control group. The treatment group involved the participants who learned using a gamified e-learning system. The control group involved the participants who learned in a traditional classroom. Both groups studied the same learning material and the main difference is the provision of gamification in an elearning system. There are six hypotheses in this study, as presented in Table 1.

Table 1. The experimental hypotheses of this study

\begin{tabular}{|c|l|}
\hline No. & \multicolumn{1}{|c|}{ Hypothesis } \\
\hline 1 & $\begin{array}{l}\text { Gamification enhances the learning outcome of } \\
\text { students. }\end{array}$ \\
\hline 2 & $\begin{array}{l}\text { Gamification improves the attention level of } \\
\text { students. }\end{array}$ \\
\hline 3 & $\begin{array}{l}\text { Gamification improves the relevance level of } \\
\text { students. }\end{array}$ \\
\hline 4 & $\begin{array}{l}\text { Gamification improves the confidence level of } \\
\text { students. }\end{array}$ \\
\hline 5 & $\begin{array}{l}\text { Gamification improves the satisfaction level of } \\
\text { students. }\end{array}$ \\
\hline 6 & $\begin{array}{l}\text { Gamification enhances the learning motivation of } \\
\text { students. }\end{array}$ \\
\hline
\end{tabular}

\subsection{Research Instruments}

The instruments used in the experiment include the gamified e-learning system, learning material related to the application domain, and the measurement tools. These research instruments are detailed as follows.

Gamified E-Learning System. A gamified elearning system was implemented in order to evaluate the effect of gamification on learning outcomes and motivation. The system was implemented based on a validated gamification framework for developing e-learning systems [29]. The system incorporated a number of game mechanisms and components, including points, time pressure, levels, badges, rewards, feedback and leader-board. The gamified e-learning system was tested by 28 experts from the University of Ha'il, Saudi Arabia, in the fields of computer science $(N=$ 4), educational technology $(N=15)$, education $(N=6)$ and Arabic language $(N=3)$. The system was hosted in a Web server so that it can be accessed via an internet browser. All the experts were able to access the system to investigate and comment on several aspects of the system, including system design, learning material presentation, reliability and accessibility issues. The suggestions and comments were collected and then taken into account to improve the system to be used in the main experiment. Figure 1. shows a screenshot example of the gamified e-learning system homepage.

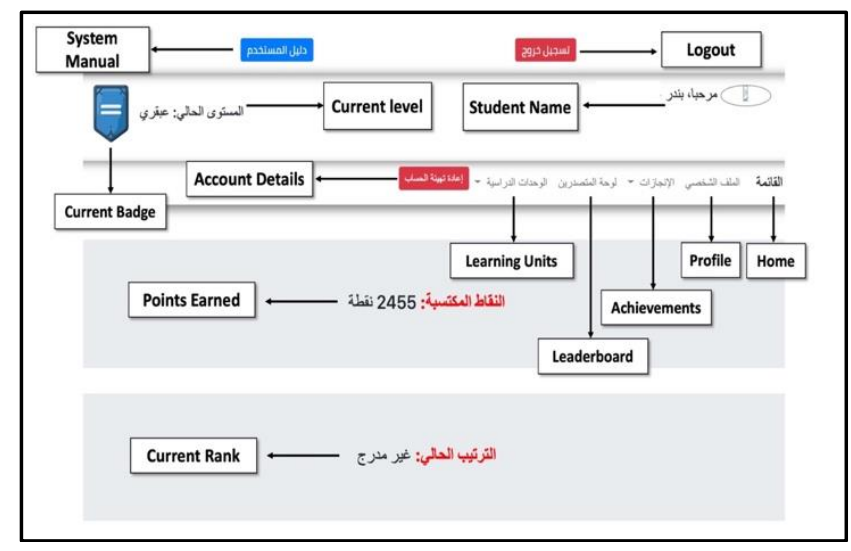

Figure 1. A homepage screenshot of the gamified $e$ learning system

Learning Material. The application domain of this study is Arabic language, and the learning material was selected from an official study book approved by the Ministry of Education in Saudi Arabia for the sixth-grade students on Arabic language. Three different learning domains of Arabic language are considered and represented in the gamified e-learning system. These domains include language style, language classification and grammatical rules. Each domain contains two learning units, and each unit 
involves a number of lessons where each has some learning concepts to be studied by the students. Figure 2. presents an example of a specific learning lesson.

Measurement Tools. The study utilized paperpencil testing on the application domain to measure the learning outcome of students. The tests include a pre-test and a post-test. Students took these two tests in both experimental conditions (i.e., the treatment condition and the control condition). The pre-test was taken by students before the experiment to determine their prior knowledge levels. The post-test was given immediately after completing all the learning tasks in the experiment. For each test, there were 24 multiplechoice questions, each with three answer options. Each question, when answered correctly, has a onepoint value so that the maximum points for each test is 24. All the tests were similar except for the formulation and order of questions and their answer options. The tests were validated by 25 experts specialized in the application domain of the experiment (i.e., Arabic language). The key points taken into account by the experts were the consideration of test suitability to the students, formulation of questions and their option answers, assessment of each question to ensure that it measures what it is supposed to measure, checking the overall test and providing comments on some ways to improve the test. These points were carefully considered to generate the final version of each test. Furthermore, there was good reliability of the pre-test and the post-test test as assessed by a Cronbach alpha having the values of 0.92 and 0.78 , respectively.

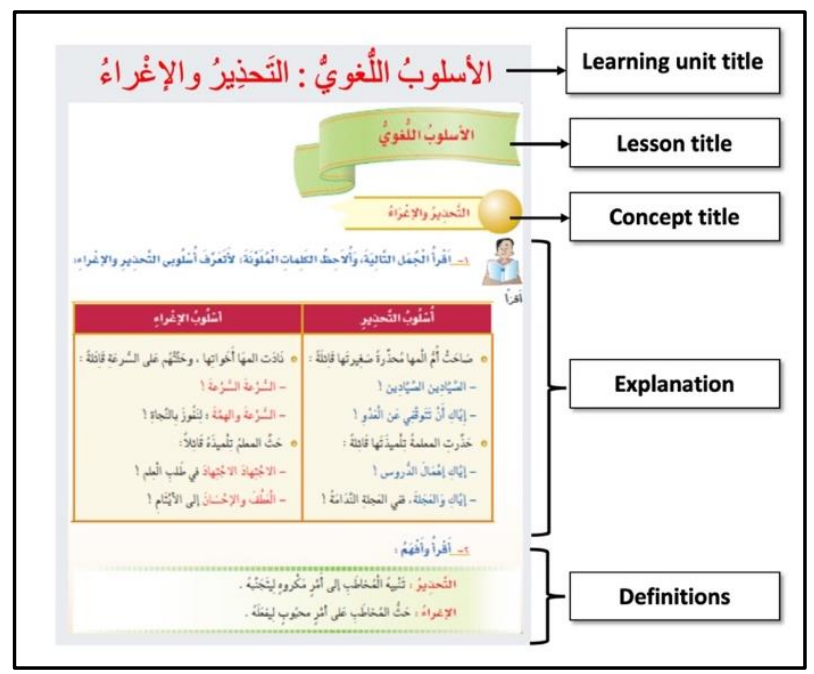

Figure 2. A learning lesson as an example of learning material that are represented in the system

The study also utilized questionnaires about learning motivation in Arabic language learning. The Instructional Material Motivation Survey (IMMS) questionnaire was used [30], [31]. This questionnaire was adapted to fit the learning content. This tool was developed to identify the learning motivation of participants. IMMS contains four dimensions (attention, relevance, confidence and satisfaction). The tool also comes with a validated and reliable questionnaire containing 36 items with five-level Likert-style rating scales, ranging from 1 (not true) to 5 (very true). Each dimension of this tool can be measured independently in addition to the scale of overall learning motivation. All four dimensions were included in this study. The attention dimension involved 12 items with Cronbach's alpha value of 0.69 . The relevance dimension consisted of 12 items with Cronbach's alpha value of 0.68 . The confidence dimension contained 12 items with Cronbach's alpha value of 0.65 . The satisfaction dimension included 12 items with Cronbach's alpha value of 0.70 . The overall Cronbach's alpha value of all the dimensions of IMMS was 0.71. These values indicate a satisfactory level of consistency of the scale used to measure learning motivation.

\subsection{Research Sample}

Recruiting all the population who are involved in the sixth grade studying a course on Arabic language (i.e., the application domain) in elementary schools in Saudi Arabia is challenging. Therefore, a random selection of two elementary schools among the registered schools in the city of Ha'il, Saudi Arabia, was made. Both selected schools had only one section of sixth-grade students. Also, one of the sections was selected randomly to be the treatment group ( $N=28$ students) and the other section was decided to be the control group ( $N=30$ students).

The main reason for selecting two independent schools is to avoid the John Henry effect and the interaction effect between participants. The John Henry effect can occur when a participant is aware of their status of being in a control group so that they work harder and try to outperform their peers in the experimental group [32]. Interaction and sharing experience between participants can happen when experimenting in one school. These issues are taken into account in this experiment. Additionally, the age of students in both groups was ranged between 11-12 years old, and they are all males. So, the age and gender variables were controlled in the experiment to avoid any variances between the experimental groups. The culture, spoken language and economic levels of the participants in both schools are assumed to be almost similar since they come from a similar background. As a result, reasonable comparisons between the treatment group and the control group can be ensured in the experiment. 


\subsection{Experimental Procedure}

The experiment was conducted in nine weeks, as presented in Figure 3. The first week involved preparation, collecting consent forms of participation, and completing the pre-test. The following seven weeks involved the study of learning material related to a course on Arabic language. In each week, there were four learning sessions, and each session lasted for about 45 minutes. The treatment group used the gamified e-learning system only in these sessions. The control group studied the same learning material via a traditional classroom. The learning material and the learning duration were the same for both groups. However, the difference was in the way that they learn either by using the gamified e-learning system or in the traditional classroom according to their assigned condition. In the ninth week, all participants, in both groups, completed the post-test and the learning motivation questionnaire.

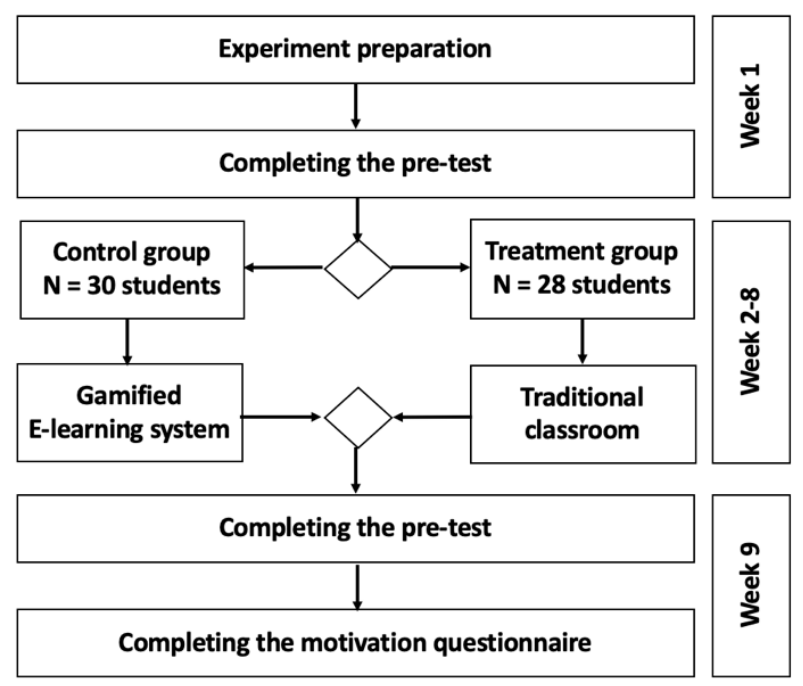

Figure 3. The experimental procedure

\section{Results}

There were 58 male participants involved in this study. They were sixth-grade students from two public elementary schools in the city of Ha'il, Saudi Arabia. The treatment group had 28 participants, and the control group involved 30 participants.

An independent $t$-test at the level of 0.05 was run after checking data distribution and variance levels to assess the difference between the treatment group and the control group for each of the experimental variables including learning outcome, the levels of attention, relevance, confidence and satisfaction in addition to the overall learning motivation. The next sub-sections detail the result of each variable.

\subsection{Learning Outcome}

The learning outcomes are reported detailing the results related to each learning domain on Arabic language (language style, language classification and grammatical rules) in addition to the overall learning outcome. The overall result of the pre-test was no statistically significant difference between the treatment group $(\mathrm{M}=11.14, \mathrm{SD}=3.01)$ and the control group $(\mathrm{M}=11.90, \mathrm{SD}=3.41), \mathrm{t}(56)=-0.89, \mathrm{p}$ $=0.37$. Also, there was no statistically significant difference found between the experimental conditions for each learning domain, as presented in Table 2 .

Table 2. The pre-test results (treatment group $=28$ participants, control group $=30$ participants)

\begin{tabular}{|c|c|c|c|c|c|c|}
\hline $\begin{array}{c}\text { Learning } \\
\text { Domain }\end{array}$ & Group & M & SD & $t$ value & df & Sig. \\
\hline \multirow{2}{*}{$\begin{array}{l}\text { Language } \\
\text { Style }\end{array}$} & Treatment & 4.83 & 1.44 & \multirow{2}{*}{-0.031} & \multirow{2}{*}{56} & \multirow{2}{*}{0.98} \\
\hline & Control & 4.82 & 1.46 & & & \\
\hline \multirow{2}{*}{\begin{tabular}{|l|} 
Language \\
Classification \\
\end{tabular}} & Treatment & 4.11 & 1.48 & \multirow{2}{*}{0.878} & \multirow{2}{*}{56} & \multirow{2}{*}{0.38} \\
\hline & Control & 3.77 & 1.47 & & & \\
\hline \multirow{2}{*}{$\begin{array}{l}\text { Grammatical } \\
\text { Rules }\end{array}$} & Treatment & 2.79 & 1.37 & \multirow{2}{*}{-1.32} & \multirow{2}{*}{56} & \multirow{2}{*}{0.19} \\
\hline & Control & 3.30 & 1.58 & & & \\
\hline \multirow{2}{*}{ Overall } & Treatment & 11.14 & 3.01 & \multirow{2}{*}{-0.89} & \multirow{2}{*}{56} & \multirow{2}{*}{0.37} \\
\hline & Control & 11.90 & 3.41 & & & \\
\hline
\end{tabular}

These particular findings of the pre-test indicate that all participants had the same knowledge level before the experiment on the application domain of this study. Therefore, reasonable comparisons between the experimental groups could be made, and that any difference found between the two experimental groups can be caused by the independent variable (i.e., the provision of gamification in an e-learning system).

About the post-test results, there is a statistically significant difference between the treatment group and the control group for each of the learning domains and the overall results, as presented in Table 3. Generally, the overall results of the post-test indicate that the treatment group $(\mathrm{M}=19.46, \mathrm{SD}=$ 2.69) had better post-test results than the control group $(\mathrm{M}=12.57, \mathrm{SD}=3.94)$ with a statistically significant difference, $\mathrm{t}(56)=7.84, \mathrm{p}=0.000$. According to these results, the hypothesis (H1) is confirmed, and it can be suggested that learning by using the gamified e-learning system yields significantly better learning outcomes than when learning in a traditional classroom. 
Table 3. The post-test results (treatment group $=28$ participants, control group $=30$ participants)

\begin{tabular}{|c|c|c|c|c|c|c|}
\hline $\begin{array}{l}\text { Learning } \\
\text { Domain }\end{array}$ & Group & $\mathbf{M}$ & SD & t value & df & Sig. \\
\hline \multirow{2}{*}{$\begin{array}{l}\text { Language } \\
\text { Style }\end{array}$} & Treatment & 7.14 & 1.11 & \multirow{2}{*}{5.12} & \multirow{2}{*}{56} & \multirow{2}{*}{0.000} \\
\hline & Control & 5 & 1.98 & & & \\
\hline \multirow{2}{*}{$\begin{array}{c}\text { Language } \\
\text { Classification }\end{array}$} & Treatment & 5.79 & 1.28 & \multirow{2}{*}{6.14} & \multirow{2}{*}{56} & \multirow{2}{*}{0.000} \\
\hline & Control & 3.47 & 1.63 & & & \\
\hline \multirow{2}{*}{$\begin{array}{c}\text { Grammatical } \\
\text { Rules }\end{array}$} & Treatment & 6.54 & 1.48 & \multirow{2}{*}{5.60} & \multirow{2}{*}{56} & \multirow{2}{*}{0.000} \\
\hline & Control & 4.10 & 1.81 & & & \\
\hline \multirow{2}{*}{ Overall } & Treatment & 19.46 & 2.69 & \multirow{2}{*}{7.84} & \multirow{2}{*}{56} & \multirow{2}{*}{0.000} \\
\hline & Control & 12.57 & 3.94 & & & \\
\hline
\end{tabular}

\subsection{Learning Motivation}

The results of the four dimensions related to learning motivation, including the levels of attention, relevance, confidence and satisfaction, are reported. In terms of the attention level results, there was no statistically significant difference between the treatment group $(\mathrm{M}=43.107, \mathrm{SD}=7.0571)$ and the control group $(\mathrm{M}=42.700, \mathrm{SD}=6.873), \mathrm{t}(56)=$ $0.223, \mathrm{p}=0.852$. Therefore, the hypothesis $(\mathrm{H} 2)$ is not confirmed, and it can be suggested that learning by using the gamified e-learning system does not yield significantly better results in terms of the attention level than when learning in a traditional classroom.

About the relevance level results, there was a statistically significant difference between the treatment group $(\mathrm{M}=37.750, \mathrm{SD}=5.096)$ and the control group $(\mathrm{M}=27.100, \mathrm{SD}=6.059), \mathrm{t}(56)=$ 7.217, $\mathrm{p}=0.000$. Thus, the hypothesis $(\mathrm{H} 3)$ is confirmed, and it can be suggested that learning by using the gamified learning system yields significantly better results in terms of relevance level than when learning in a traditional classroom.

Regarding the results of the confidence level, there were no statistically significant differences between the treatment group $(\mathrm{M}=32.892, \mathrm{SD}=4.976)$ and the control group $(\mathrm{M}=33.200, \mathrm{SD}=2.746), \mathrm{t}(56)=$ $0.294, p=0.770$. Accordingly, the hypothesis $(\mathrm{H} 4)$ is not confirmed, and it can be suggested that learning by using the gamified learning system does not yield significantly better results in terms of confidence level than when learning in a traditional classroom.

The results of the satisfaction level indicated that there were statistically significant differences between the treatment group $(\mathrm{M}=26.357, \mathrm{SD}=$ $3.508)$ and the control group $(\mathrm{M}=15.033, \mathrm{SD}=$ 7.246), $\mathrm{t}(56)=7.48, \mathrm{p}=0.00$. Hence, the hypothesis (H5) is confirmed, and it can be suggested that learning by using the gamified learning system yields significantly better results in terms of satisfaction level than when learning in a traditional classroom.

The overall learning motivation results indicated that there were statistically significant differences between the treatment group $(\mathrm{M}=140.107, \mathrm{SD}=$ $15.739)$ and the control group $(\mathrm{M}=118.033, \mathrm{SD}=$ $15.160), t(56)=5.44, p=0.00$. So, the hypothesis (H6) is confirmed, and it can be suggested that learning using the gamified learning system yields significantly better overall motivation than when learning in a traditional classroom.

\section{Discussion and Conclusion}

This paper contributes to the body of knowledge by the provision of a controlled experiment investigating the effect of gamification on learning and by the obtained results. The experiment was conducted with 58 sixth-grade elementary school students using a gamified learning environment for Arabic language learning. The results indicated that learning by using a gamified e-learning system yields a statistically significant difference in terms of learning outcome and motivation when compared to learning in traditional classrooms. Therefore, different game elements should be incorporated into e-learning systems to support and motivate students in the learning process.

The study filled a research gap by answering the main research question, "Does gamification in elearning systems enhance the learning outcomes and learning motivation of sixth-grade students in learning a course on Arabic language?". The study explored the effect of gamification, particularly on young students studying Arabic language as one of the first studies in that regard. The results obtained by the conducted experiment were mostly positive in terms of learning outcome and learning motivation. The hypothesis results are presented in Table 4.

Table 4. Hypothesis results

\begin{tabular}{|c|l|c|}
\hline No. & \multicolumn{1}{|c|}{ Hypothesis } & Support \\
\hline 1 & $\begin{array}{l}\text { Gamification enhances the learning } \\
\text { outcome of students. }\end{array}$ & Yes \\
\hline 2 & $\begin{array}{l}\text { Gamification improves the attention } \\
\text { level of students. }\end{array}$ & No \\
\hline 3 & $\begin{array}{l}\text { Gamification improves the relevance } \\
\text { level of students. }\end{array}$ & Yes \\
\hline 4 & $\begin{array}{l}\text { Gamification improves the } \\
\text { confidence level of students. }\end{array}$ & Yes \\
\hline 5 & $\begin{array}{l}\text { Gamification improves the } \\
\text { satisfaction level of students. }\end{array}$ & Yes \\
\hline 6 & $\begin{array}{l}\text { Gamification enhances the overall } \\
\text { learning motivation of students. }\end{array}$ & \multicolumn{2}{|l}{} \\
\hline
\end{tabular}

However, there was no effect found regarding the level of attention and the level of confidence. The attention level was not as expected since gamification is assumed to enable the students to pay more attention while studying. The main reason could be that the students in the control group (i.e., in the traditional classroom) were possibly motivated 
adequately by the instructor to pay full attention even though no gamification was enabled. As a result, the level of attention in the traditional classroom might be increased due to the exceptional level of the instructor in supporting and motivating students in classrooms. Therefore, there was no difference in terms of the attention level between the treatment group who used the gamified e-learning system and the control group.

This issue is also applied to the results related to the confidence level as no difference was found between the two experimental groups. The students in the experiment could felt that using a computer to learn was new to them and they required some time to adapt to the novel learning situation created by the gamified system so that their confidence levels were undesirably affected.

This study provided a comparison between two extreme cases as a useful preliminary approach. This particular finding generated another research question that needs to be further explored comparing a gamified e-learning system with a traditional elearning system where gamification is disabled rather than comparing with a traditional classroom.

The overall learning experience when using the gamified e-learning system was encouraging as reported regarding the levels of relevance and satisfaction in addition to the overall learning motivation and learning outcome.

The used gamified e-learning system integrated multiple game elements including points, time pressure, levels, badges, rewards, feedback and leader-boards. Any effect found could be caused mainly to the incorporation of the pre-mentioned game elements and are not linked to a specific one. Some studies which incorporated one to three game elements found conflicting results on the learning effect [25], [26]. The findings reported in this study confirm that taking into account different game elements can motivate students to learn, which enhances their learning gain. The findings are also aligned with several related studies on gamification that generated a positive effect on learning [13], [16], [19], [27].

The point highlighted by [8] emphasizes the importance of both the gamification context and the users who used the gamified system; these two aspects play an important role in determining the effect of the integration of gamification in e-learning systems as a motivation tool. The study presented in this paper differs from previous attempts in terms of the application domain (i.e., Arabic language), the culture where the experiment took place, the longterm learning study and the controlled and thorough experimental evaluation.

There are various future research directions that can be followed. Although this study was applied to young male students only and generated positive findings, the effect of gamification can be explored for young female students in future experiments so that gender differences can be established.

Another future research direction could incorporate social and collaborative features besides gamification in e-learning systems in order to share knowledge and communicate ideas between peers. Also, one of the trending topics in online education is to personalize and adapt learning material according to the different students' characteristics such as learning style, personality and knowledge level. So, an investigation of how to incorporate both personalization and gamification is desirable in future studies [33].

No matter the features and learning mechanics incorporated in future online-learning research, paying careful attention to designing thorough and controlled experiments to investigate the effect of gamification is essential. The evaluation method of this study is also detailed in a way that can be beneficial to future research on gamification.

\section{References}

[1] Rodrigues, H., Almeida, F., Figueiredo, V., \& Lopes, S. L. (2019). Tracking e-learning through published papers: A systematic review. Computers \& Education, 136, 87-98.

[2] Ally, M. (2004). Foundations of educational theory for online learning. Theory and practice of online learning, 2, 15-44.

[3] Welsh, E. T., Wanberg, C. R., Brown, K. G., \& Simmering, M. J. (2003). E-learning: emerging uses, empirical results and future directions. international Journal of Training and Development, 7(4), 245258.

[4] Xie, H., Chu, H. C., Hwang, G. J., \& Wang, C. C. (2019). Trends and development in technologyenhanced adaptive/personalized learning: A systematic review of journal publications from 2007 to 2017. Computers \& Education, 140, 103599.

[5] Turan, Z., Avinc, Z., Kara, K., \& Goktas, Y. (2016). Gamification and education: Achievements, cognitive loads, and views of students. International Journal of Emerging Technologies in Learning (iJET), 11(07), 64-69.

[6] Hursen, C., \& Bas, C. (2019). Use of gamification applications in Science Education. International Journal of Emerging Technologies in Learning (iJET), 14(01), 4-23.

[7] Deterding, S., Dixon, D., Khaled, R., \& Nacke, L. (2011, September). From game design elements to gamefulness: defining" gamification". In Proceedings of the 15th international academic MindTrek conference: Envisioning future media environments (pp. 9-15).

[8] Hamari, J., Koivisto, J., \& Sarsa, H. (2014, January). Does gamification work?--a literature review of empirical studies on gamification. In 2014 47th Hawaii international conference on system sciences (pp. 3025-3034). IEEE. 
[9] Simões, J., Redondo, R. D., \& Vilas, A. F. (2013). A social gamification framework for a K-6 learning platform. Computers in Human Behavior, 29(2), 345-353.

[10] Cone, B. D., Irvine, C. E., Thompson, M. F., \& Nguyen, T. D. (2007). A video game for cyber security training and awareness. Computers \& Security, 26(1), 63-72.

[11] Kasurinen, J., \& Knutas, A. (2018). Publication trends in gamification: A systematic mapping study. Computer Science Review, 27, 33-44.

[12] Koivisto, J., \& Hamari, J. (2019). The rise of motivational information systems: A review of gamification research. International Journal of Information Management, 45, 191-210.

[13] DomíNguez, A., Saenz-De-Navarrete, J., DeMarcos, L., FernáNdez-Sanz, L., PagéS, C., \& MartîNez-HerráIz, J. J. (2013). Gamifying learning experiences: Practical implications and outcomes. Computers \& education, 63, 380-392.

[14] Sailer, M., Hense, J. U., Mayr, S. K., \& Mandl, H. (2017). How gamification motivates: An experimental study of the effects of specific game design elements on psychological need satisfaction. Computers in Human Behavior, 69, 371-380.

[15] Kyewski, E., \& Krämer, N. C. (2018). To gamify or not to gamify? An experimental field study of the influence of badges on motivation, activity, and performance in an online learning course. Computers \& Education, 118, 25-37.

[16] da Rocha Seixas, L., Gomes, A. S., \& de Melo Filho, I. J. (2016). Effectiveness of gamification in the engagement of students. Computers in Human Behavior, 58, 48-63.

[17] Su, C. H., \& Cheng, C. H. (2015). A mobile gamification learning system for improving the learning motivation and achievements. Journal of Computer Assisted Learning, 31(3), 268-286.

[18] Yildirim, I. (2017). The effects of gamification-based teaching practices on student achievement and students' attitudes toward lessons. The Internet and Higher Education, 33, 86-92.

[19] Park, J., Liu, D., Mun, Y. Y., \& Santhanam, R. (2019). GAMESIT: A gamified system for information technology training. Computers \& Education, 142, 103643.

[20] Baptista, G., \& Oliveira, T. (2019). Gamification and serious games: A literature meta-analysis and integrative model. Computers in Human Behavior, 92, 306-315.

[21] Tan, M., \& Hew, K. F. (2016). Incorporating meaningful gamification in a blended learning research methods class: Examining student learning, engagement, and affective outcomes. Australasian Journal of Educational Technology, 32(5).
[22] Omotosho, A., Tyoden, T., Ayegba, P., \& Ayoola, J. (2019). "A Gamified Approach to Improving Student's Participation in Farm Practice--A Case Study of Landmark University," International Journal of Emerging Technologies in Learning (iJET), 13(05), 94-109.

[23] Strmečki, D., Bernik, A., \& Radošević, D. (2015). Gamification in e-learning: Introducing gamified design elements into e-learning systems. Journal of Computer Science, 11(12), 1108-1117.

[24] Ibanez, M. B., Di-Serio, A., \& Delgado-Kloos, C. (2014). Gamification for engaging computer science students in learning activities: A case study. IEEE Transactions on learning technologies, 7(3), 291301.

[25] Filsecker, M., \& Hickey, D. T. (2014). A multilevel analysis of the effects of external rewards on elementary students' motivation, engagement and learning in an educational game. Computers \& Education, 75, 136-148.

[26] Attali, Y., \& Arieli-Attali, M. (2015). Gamification in assessment: Do points affect test performance?. Computers \& Education, 83, 57-63.

[27] Bicen, H., \& Kocakoyun, S. (2018). Perceptions of students for gamification approach: Kahoot as a case study. International Journal of Emerging Technologies in Learning (iJET), 13(02), 72-93.

[28] Ozcinar, Z., Zakirova, V. G., Kurbanov, R. A., \& Belyalova, A. M. (2019). Analysis of the Documents Published in the Web of Science Database on Teachers' Gamification Method: A Content Analysis. International Journal of Emerging Technologies in Learning (iJET), 14(22), 82-94.

[29] Mohammad T Alshammari.(2019). Design and Learning Effectiveness Evaluation of Gamification in e-Learning Systems. International Journal of Advanced Computer Science and Applications(IJACSA), 10(9), 204-208. http://dx.doi.org/10.14569/IJACSA.2019.0100926

[30] Keller, J. M. (1987). Development and use of the ARCS model of instructional design. Journal of instructional development, 10(3), 2-10.

[31] Keller, J. M. (2010). Tools to support motivational design. In Motivational design for learning and performance (pp. 267-295). Springer, Boston, MA.

[32] Saretsky, G. (1972). The OEO PC experiment and the John Henry effect. The Phi Delta Kappan, 53(9), 579-581.

[33] Jagušt, T., Botički, I., \& So, H. J. (2018). Examining competitive, collaborative and adaptive gamification in young learners' math learning. Computers \& education, 125, 444-457. 